\title{
Research on the Strategy of Improving the Effect of Enterprise Marketing in the Context of Consumption
}

\author{
Jian $\mathrm{Xu}^{1}$ \\ ${ }^{1}$ Qujing Normal University, yunnan qujing city kirin sanjiang avenue, 655011 \\ 14027400@qq.com
}

Keywords: Consumption situation; Marketing; Marketing effect; Strategy

\begin{abstract}
With the development of social economy, the purchasing power of consumers is increasing, the difference between similar products in the market is narrowed, and the transmission of goods information is not timely or asymmetric, which makes consumers face more difficulties when facing more homogeneous goods. In the marketing, the consumer situation effect can be used to guide consumer consumption better. Through the analysis of the influence of consumer situation and situation on consumer behavior, this paper puts forward the strategies to improve the marketing effect of the enterprise.

With the rapid development of social economy, the ability to buy society has been improved, but the similar products in the market to narrow the differences, commodity information transfer is not timely or asymmetrical market information intensive deepening problems, exacerbated by the homogeneity of products, making the market more competitive. Enterprises want to stand out in the fierce market competition, rely on traditional marketing methods, emphasize the marketing mix with $4 \mathrm{P}$ as the core, obviously, the advantages are not outstanding, and marketing has little effect. Enterprises must make marketing mix optimization based on the concept of modern marketing, highlight and emphasize the demands of product differentiation, and develop customized marketing strategies for enterprises.

In personalized marketing, the consumption situation is an important factor. The situation refers to the internal and external stimuli that the consumer faces, and can respond to the physiological and psychological responses of the consumer. The situation is made up of some temporary events and states, which are neither part of the marketing stimulus itself nor a consumer feature. ${ }^{[1]}$ the factors affecting consumer behavior include macro and micro environmental factors, as well as personal, social and marketing factors, and consumer situations are microcosmic factors. The consumption situation mainly emphasizes consumer's consumption process, such as specific scenes, time, weather, scene atmosphere, salesperson's service attitude, accompanying purchase partners and so on. Situation is only affected by specific scenes and time points, and scenes or time points change. For consumers, the original situation will no longer play a role. Consumption situation is generally composed of some temporary time and location and status, so the consumption situation is not the law, by chance in the consumer purchase activities, will disappear as consumers leave, nor by the consumer personal factors or product factors determined, consumption situation is relative in consumer spending in.
\end{abstract}

\section{The Composition of the Consumption Situation}

Material Environment. The physical environment is actually the material factors of consumer shopping environment, such as store location, store decoration, store the use of color, lighting, merchandise display, audio application, including material factors such as smell, these material factors will have important influence on consumer sentiment, the same material factors because of the different degree, size etc., have different effects on consumer behavior will be. As businesses tend to use sound in the sales field to create promotional atmosphere, appropriate background music can not only active site shopping atmosphere, but also can stimulate customer consumption desire, adjust the mood of the consumer, because the consumer even queue causes of anxiety can be alleviated by moderate. 
Social Environment. Social environment, also known as interpersonal context, refers to the social and environmental factors directly or indirectly influenced by others in the process of shopping, such as the guidance of salesmen, the attitude of salesmen, and the opinions of peers. The influence of social environment on consumers' purchase is relatively small. Under the condition of not buying alone, social environment will form psychological pressure to consumers to some extent, which will affect their buying behavior. Such as the impact of peer opinions and suggestions on consumers in shopping, such as the influence of salesperson's guidance, attitude and sales skills on buyer's purchase behavior.

Time. The development of business marketing needs the right time, and consumer shopping needs to be completed in a certain time. As a constituent element of the situation, time refers to the timing of marketing activities and the adequacy of shopping time when consumers consume, including the timing of activities, the concept of time, the time of shopping and the pressure of time. If the timing of the enterprises to carry out marketing activities; the fast pace of modern life, convenient way of consumption; according to the particularity of product characteristics and characteristics of consumer demand and emphasis on shopping time; consumer purchases such as the urgency will be an important part of consumer situation.

Purchase Task. The purchase task is the motive or the reason and purpose of the purchase of the purchase behavior of the consumer. In the consumer market, in the face of the same product, the purpose of consumer purchase may be different. According to the differences in the consumer's purchase purpose, there are mainly self - use purchases to meet their own needs and social purchases to meet the needs of communication. At the same time, there are differences in the demand for different purchase purposes on the product.

Previous state. The former state refers to the short-term, non persistent mental state or personal characteristics of customers' temporary mood, mood or state in the process of shopping. The previous state is mainly embodied in the cheerful, anxiety, fatigue, hunger, physical discomfort and other phenomena of consumers, has played an important role on the formation and consumption situation of these phenomena, influence the process and result of the consumer and the consumer in the process of psychological and emotional state of shopping.

\section{The Influence of Consumer Situation on Consumer Behavior}

The influence of consumer situation on consumer behavior can be analyzed from five stages, namely, consumer purchase decision confirmation, information collection, product evaluation, purchase decision and post purchase behavior.

The Impact on the Confirmation Stage of the Problem. Problem recognition is the starting point of consumer behavior, and consumers should first make clear what they want and what they need. And the needs of the consumer are aroused by the internal and external causes such as cold and heat. Store decoration, personalized color application, lighting, music and sound playing, shopping environment and other physical environment have a stimulating effect on consumers' needs, interests and desires, thus affecting their consumers' needs and behaviors.

The Impact on the Information Gathering Stage. Information collection is the prerequisite and basis for the occurrence of consumer behavior. The sources of consumers' information are mainly composed of experience, individual, public and commercial sources. In order to guide consumption better and provide information basis for decision-making, consumers should collect similar or related product information to meet their needs. The influence of consumption situation on information collection can not be ignored. If consumption demand is different, the direction and scope of information collection are different. For the same product, the task and the strength and requirement of information collection are different.

The Impact on the Product Evaluation Stage. The information collection completion will be evaluated for the alternative products. The situation factors such as the purchase of the task, the previous state and so on will affect the consumer's attitude towards the product. If the situation will be changed in different consumer awareness and understanding of the product brand beliefs; will change the objective evaluation of consumer products with specific properties will change; the 
interests of consumers of products concerns; allowing consumers to distinguish the merits of the different products and so on.

The Impact on the Purchase Decision Stage. The purchase decision stage is that consumers will choose products such as product category, attribute, brand, time, dealer, quantity, payment way and so on. In this process, peer recommendations, others' attitudes and unexpected factors will influence consumers' purchase intention. Consumers' happiness and anxiety will affect the choice of specific purchase decisions.

The Influence on the Post Purchase Behavior Stage. The post purchase behavior mainly includes the process of using, disposing and evaluating the product after purchase. In this process, the consumption situation will also have an impact on consumer behavior. Such as the site to buy on the spot when in use, the material consumption situation and social environment factors such as store, sales staff will influence consumers to use the process and effect of the product; the urgency of time affect the disposal of products; consumers will also affect the evaluation of the previous state of the product after use.

\section{Strategies to Improve the Marketing Effect of Enterprises in the Context of Consumption}

Shape the Situation of Information Acquisition. Information acquisition situations, also known as information communication situations, refer to "information receiving situations that affect consumer behavior." ${ }^{[2]}$ the difference in the way, time and place of the consumer's information on the product will have a profound impact on the consumer behavior. To win the favor of the consumer, the enterprise products must create the necessary situation of information acquisition to attract the consumer groups. Access to information can increase the shape context information display means such as through advertising, public relations, promotions and other ways in the specific context of product information dissemination, expand the scope of the spread, the difference between competitors; and through the use of collocation of physical environment, process of product characteristics, enhance the product discrimination effect of the largest; the social environment of the target consumers, targeted marketing; marketing time grasp the best time, and is conducive to the consumer, to reflect the differences of products and competitor products.

Shape The Purchase Situation. Buying context refers to the situation when consumers are buying or acquiring, usually involving the information environment, the retail environment and time pressure when buying decisions and actually buying. [3] the building of the purchase situation mainly involves three aspects: one is to emphasize the emotion of the selling field. Actively create the selling situation suitable for product sales, highlight the advantages and personality of the products, and improve the service at various stages of the product. The two is to strengthen the visual effect of service. We should pay attention not only to the visible service items, but also to the details of the service itself and the process of providing services, so as to improve the service quality and enhance the degree of customer satisfaction. The three is to increase the interaction of consumer experience. Improve consumers' participation in marketing activities and enhance customers' sense of participation.

The Modeling of the Use of the Situation. The usage situation refers to the consumer situation that the consumer faces in the process of using the product. From the perspective of the elements of consumption situation, the use of context is obviously different from the expectation of consumers and the situation of acquiring products, just as a product is playing its own function of wearing itself or playing a social function of giving a gift to a friend. There are many factors affecting the use situation such as time, social environment, and so on. If enterprises want to make use of situations to serve business marketing activities, we need to know the relationship between consumers' beliefs and situational changes and the relative importance of product characteristics. There are two key elements in the building of the situation. One is the market segmentation of the product. From the demand of consumers, the market is subdivided on a certain basis, the appropriate target market is chosen, and the corresponding marketing strategy is formulated. Two is product positioning. On the basis of market segmentation and target market selection, we should make proper market positioning for products, help consumers to make overall evaluation of them, 
give full play to product functions, and meet their needs at different time and place.

\section{Conclusion}

With the development of social economy, marketing plays an important role in the development of enterprises. Enterprise marketing, to the modern marketing concept, according to the market demand and the ability of the company, marketing strategy, formulate the optimization at the same time, in the face of the phenomenon of product homogeneity, the enterprise because of the strengthen product differentiation in marketing, personalized marketing. The elements of consumption situation have an important impact on consumer behavior. Strengthening information acquisition situation, buying situation and using context will surely improve the marketing effect of enterprises.

\section{References}

[1] C.Z. Wu: Analysis of the influence of situational factors on consumer psychology,(2008) No.12, p.64-65. (In Chinese)

[2] X.Q. Li: Marketing strategy analysis based on the thinking of consumption situation,(2015), p.85-86. (In Chinese)

[3] X. Zhang: The influence of buying situation on consumer psychology and behavior,(2014) No.23, p.73-74. (In Chinese) 